\title{
THEORETICAL STUDIES ON TRIACETONETRIPEROXIDE (TATP) DERIVATIVES TO IMPROVE THEIR PERFORMANCE
}

\author{
Zongcheng Miao ${ }^{\mathrm{a},}$, Faan $\mathrm{Li}^{\mathrm{b}}$ and Yi Luan ${ }^{\mathrm{c}, *}$ \\ aKey Laboratory of Organic Polymer Photoelectric Materials, School of Science, Xijing University, 710123 Xi'an, PR China \\ ${ }^{b}$ Department of Business Administration, School of Management and Economics, Beijing Institute of Technology, 100081 Beijing, \\ PR China \\ 'Department of Materials Physics, School of Materials Science and Engineering, University of Science and Technology Beijing, \\ 100083 Beijing, PR China
}

Recebido em 14/05/2018; aceito em 05/09/2018; publicado na web em 27/09/2018

\begin{abstract}
Density functional theory (DFT) methods are used to study on TATP derivatives at DFT-B3LYP/6-311++G (d, p) level to improve TATP's performance. The derivatives are 3,6,9-trimethyl-3,6,9-tris(trifluoromethyl)-1,2,4,5,7,8-hexaoxonane (TATP3F), 3,6,9-trimethyl-3,6,9-tris(nitromethyl)-1,2,4,5,7,8-hexaoxonane $\left(\mathrm{TATPNO}_{2}\right)$ and (3,6,9-trimethyl-1,2,4,5,7,8-hexaoxonane-3,6,9-triyl) trimethanamine $\left(\mathrm{TATPNH}_{2}\right)$. Stability and detonation performance of TATP derivatives were investigated. Detonation performance was estimated using density, heat of formation and EXPLO 5 software. Stability was evaluated by geometrical geometry and electronic structure. The simulation results reveal that $\mathrm{TATPNO}_{2}$ has a best oxygen balance, detonation performance $\left(\mathrm{Q}=5424 \mathrm{~kJ} \mathrm{~kg}{ }^{-1}\right.$, $\mathrm{P}=23.7 \mathrm{Gpa}, \mathrm{D}=7699 \mathrm{~m} \mathrm{~s}^{-1}$ ) and insensitivity. Since TATPNO $\mathrm{N}_{2}$ is more excellent than TATP and traditional explosive TNT in detonation performance, it is a candidate of novel high energy density materials.
\end{abstract}

Keywords: TATP; density functional theory (DFT); detonation performance; sensitivities.

\section{INTRODUCTION}

High energy density materials (HEDMs) have attracted significant attention owing to their massive usage as explosive, propellants, pyrotechnic agents, gas generators and so on in a wide range of applications. ${ }^{1-4}$

A potentially initiating explosive peroxide triacetonetriperoxide (TATP), which is shown in Figure 1, is not viewed as HEDMs due to its poor performance. However, TATP has been extensively used by terrorists in terrorist attack because of its low-cost and simple production process. ${ }^{5,6}$ In the meantime, the obvious advantage of TATP is that it has an affluent oxygen content. There are two ways to improve the oxygen balance of HEDMs. One is to introduce nitro and difluoramino, ${ }^{7,8}$ and the other is to use oxygen-rich skeletons. ${ }^{9}$ TATP, with six oxygen atoms in a ring, is expected to be a promising energetic skeleton. The disadvantage of TATP is its poor sensitivity and detonation performance ${ }^{10}$ and modifications are needed to improve TATP's performance for meeting the requirements of HEDMs in military and civilian use.

In this paper, we proposed to add three commonly energetic and stable substituents, $-\mathrm{CF}_{3},-\mathrm{NO}_{2}$ and $-\mathrm{NH}_{2}$, separately to the rich oxygen skeleton of TATP in order to lower its sensitivity and enhance its detonation performance. The three new compounds are named 3,6,9-trimethyl-3,6,9-tris(trifluoromethyl)-1,2,4,5,7,8-hexaoxonane (TATP3F), 3,6,9-trimethyl-3,6,9-tris(nitromethyl)-1,2,4,5,7,8hexaoxonane $\left(\mathrm{TATPNO}_{2}\right)$ and (3,6,9-trimethyl-1,2,4,5,7,8hexaoxonane-3,6,9-triyl)trimethanamine $\left(\mathrm{TATPNH}_{2}\right)$, respectively (Figure 2).

The properties of these three new compounds were studied by theoretical calculation. Theoretical calculations based on quantum chemistry have been accepted as a time-saving tool to select the expected candidates for effectively minimizing expensive and dangerous experimental tests. ${ }^{11,12}$ This paper presents crystal

*e-mail: yiluan@ustb.edu.cn

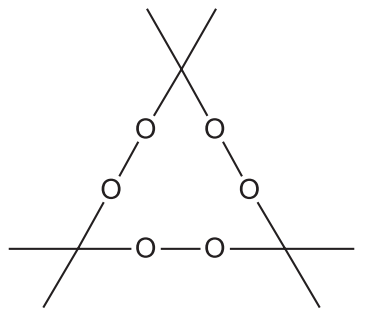

Figure 1. Chemical structure of TATP

density $\left(\rho_{\text {cry }}\right)$ and heat of formation $\left(\Delta H_{f}\right)$ for calculating detonation performance of title compounds, such as explosion heat (Q), detonation velocity (D) and detonation pressure (P). Besides, this paper also presents electrostatic potential analysis (ESP) and energy gap $\left(\Delta \mathrm{E}_{\mathrm{LUMO-Hомо}}\right)$ of the highest occupied molecular orbital (HOMO) and the lowest unoccupied molecular orbital (LUMO) for calculating sensitivity of title compounds. Their characteristics were used to compare with TATP's one to screen new energetic candidates with excellent performance and acceptable sensitivity. These results will provide theoretical support for molecular design of novel HEDMs.

\section{COMPUTATIONAL METHODS}

The calculations were performed with the Gaussian 09 package. ${ }^{13}$ DFT-B3LYP methods with the $6-311 \mathrm{G}++(\mathrm{d}, \mathrm{p})$ basis set ${ }^{14-16}$ were adopted to optimize the molecular structures and predict the heats of formation. Previous studies have shown that the $6-311 \mathrm{G}++(\mathrm{d}, \mathrm{p})$ basis set is able to precisely predict the molecular structures and energies of energetic organic compounds..$^{17,18}$ All structures were identified to be local minima without imaginary frequencies.

Bond lengths, especially three $\mathrm{O}-\mathrm{O}$ bond lengths, of title compounds were one of the major focuses of the calculation study. These bond lengths are used to compare to the ones of TATP. Generally speaking, the bond length is closely related to the bond stability: the longer the bond is, the less stable the bond is. ${ }^{19}$ 


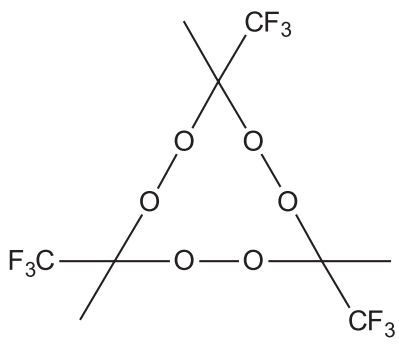

TATP3F
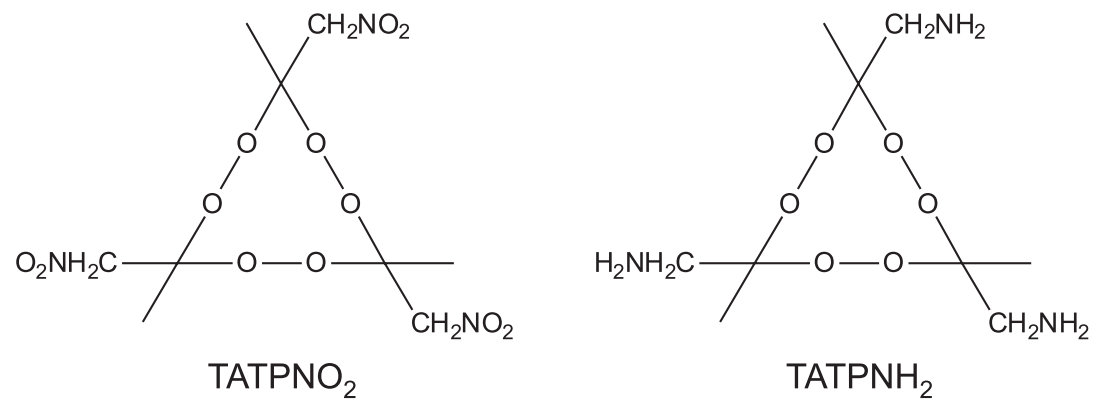

Figure 2. Chemical structure of TATP derivatives

The crystals density is an important parameter of energetic materials to predict detonation performance. It is predicted by using Equation (1) with considering the intermolecular interactions in crystals. In the Equation, $\mathrm{M}$ is the molecular weight, and $\mathrm{V}_{\mathrm{m}}$ is the molecular volume defined as inside a contour of 0.001 au density that was evaluated using a Monte Carlo integration. Besides, $\sigma_{\text {tot }}^{2}$ and $\mathrm{v}$ is total variance on the molecular surface and electrostatic balance parameter, respectively. The two parameters were obtained by Multiwfn program. ${ }^{20}$ Finally, in order to make a better account for intermolecular interactions and enhance the accuracy of predictions, Politzer et al..$^{21}$ proposed to use correction parameters $\alpha, \beta$ and $\gamma$. They compared experimental and calculated densities of 36 compounds and revealed that $\alpha, \beta$ and $\gamma$ is $0.9183,0.0028,0.0443$, respectively.

$$
\rho=\alpha\left(\frac{M}{V_{m}}\right)+\beta\left(v \sigma_{t o t}^{2}\right)+\gamma
$$

The heat of formation is another important parameter to predict
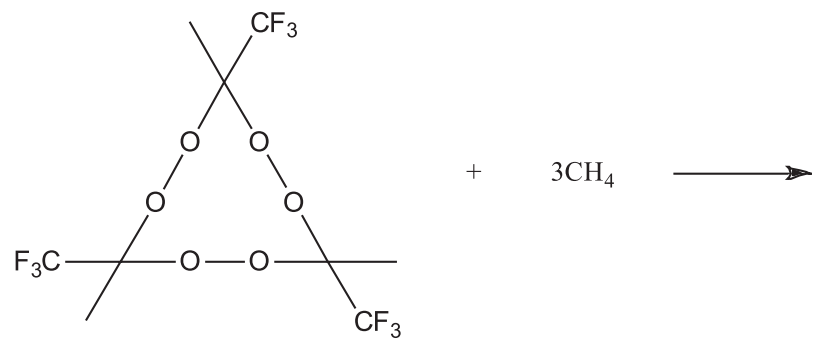

Scheme 1. Isodesmic reactions of TATP $3 F$
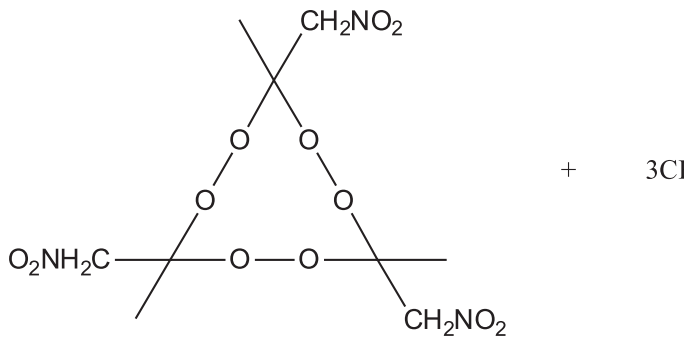

$3 \mathrm{CH}$

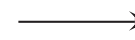

Scheme 2. Isodesmic reactions of $\mathrm{TATPNO}_{2}$
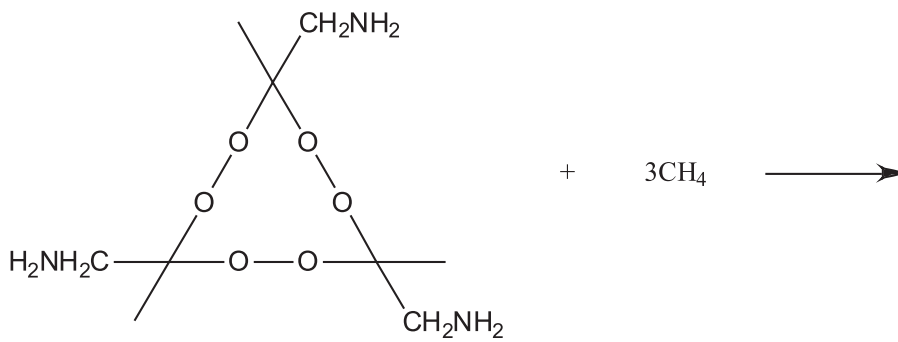

Scheme 3. Isodesmic reactions of TATPNH detonation performance. It was predicted by the Equation (2)-(4) with isodesmic reactions (Schemes 1-3). Equation (2) was used to calculate the gas phase heats of formation of the title compounds where $\Delta_{\mathrm{f}} \mathrm{H}_{\mathrm{P}}$ and $\Delta_{\mathrm{f}} \mathrm{H}_{\mathrm{R}}$ are the heat of formation of the products and the reactants in isodesmic reactions, respectively. $\Delta \mathrm{E}_{0}$ is the change in total energy between the products and the reactants at $0 \mathrm{~K} . \Delta \mathrm{E}_{\mathrm{ZPE}}$ is the difference between the zero-point energy $\left(\mathrm{E}_{\mathrm{ZPE}}\right)$ of the products and the reactants, and $\Delta \mathrm{H}_{\mathrm{T}}$ is the thermal correction from $0 \mathrm{~K}$ to $298 \mathrm{~K}$. $\Delta \mathrm{nRT}$ is equal to zero here. ${ }^{22}$

$$
\begin{gathered}
\Delta_{\mathrm{r}} H_{298}=\sum \Delta_{f} H_{P}-\sum \Delta_{f} H_{R} \\
=\Delta E_{0}+\Delta E_{Z P E}+\Delta H_{T}+\Delta n R T \\
\Delta_{f} H(c)=\Delta_{f} H(g)-\Delta H_{s u b} \\
\Delta H_{s u b}=a\left(A_{s}\right)^{2}+b\left(v \sigma_{\text {tot }}^{2}\right)^{0.5}+c
\end{gathered}
$$

Equation (3) and (4) was used to calculate the condense phase

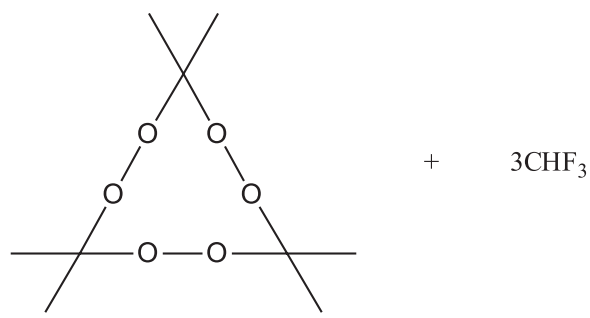


heat of formation of the title compounds where $\Delta_{\mathrm{f}} \mathrm{H}(\mathrm{c}), \Delta_{\mathrm{f}} \mathrm{H}(\mathrm{g})$ and $\Delta \mathrm{H}_{\text {sub }}$ is the condense phase heat of formation, the gas phase heat of formation and enthalpy of sublimation, respectively. The meaning and value of $v$ and $\sigma_{\text {tot }}^{2}$ here is the same to Equation (1), and as is molecular surface area. In Equation (4), a, b, c developed by Politzer ${ }^{23}$ is $0.000267,1.650087,2.966078$, respectively.

Based on the condense phase heat of formation and crystals density, explosion heat (Q), detonation velocity (D) and detonation pressure $(\mathrm{P})$ of the title compounds can be calculated by EXPLO 5 (v6.01), a program widely applied as an important tool to compute detonation performance. ${ }^{24-26}$

The energy gap $\Delta \mathrm{E}_{\text {LUмо-номо }}$ between HOMO and LUMO is an important parameter of energetic materials to predict kinetic stability. It is worth noting that stability refers to the stability of the compound to photoinitiated electron-transfer processes. ${ }^{27}$ The energy gap shows that the intramolecular charges transfer from the electron donor to the electron acceptor. The higher the magnitudes are, the less stable the title compounds are.

The electrostatic potential (ESP) is another important parameter of energetic materials to predict stability, especially nucleophilic and electrophilic sites, as well as the molecular recognition mode for a long time. Their theoretical basis is that molecules always tends to approach each other. ${ }^{20,28,29}$ The ESP can be shown in a map in which the blue and red spheres correspond to electrophilic and nucleophilic ESP surfaces, respectively.

\section{RESULTS AND DISCUSSION}

\section{Geometrical structures}

The optimized geometries of the most stable conformers were calculated with B3LYP/6-311G++ (d, p) method. The optimized structure of TATP and its derivatives compounds were shown in Figure 3. All harmonic frequencies and summaries of their output parameters were shown in Supplementary Material. It is reported ${ }^{30}$ that due to the weak $\mathrm{O}-\mathrm{O}$ bond, peroxides undergo facile thermal decomposition. Since the bond length is closely related to the bond stability, the O-O bond length is very important to title compounds.

Three O-O bond lengths of these compounds were used to compare to the counterpart of TATP, shown in Table 1. Generally speaking, the bond length is closely related to the bond stability and the longer the bond is, the less stable the bond is. From the Figure 3 and Table 1, it can be seen that O-O bond lengths of TATP3F and

Table 1. the O-O bond lengths of TATP and TATP derivatives

\begin{tabular}{lccc}
\hline Compound & O5-O15 & O10-O11 & O4-O6 \\
\hline TATP & 1.459 & 1.459 & 1.462 \\
TATP3F & 1.459 & 1.455 & 1.461 \\
TATPNH $_{2}$ & 1.461 & 1.460 & 1.465 \\
TATPNO $_{2}$ & 1.459 & 1.455 & 1.462 \\
\hline
\end{tabular}

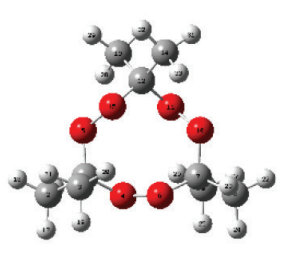

TATP

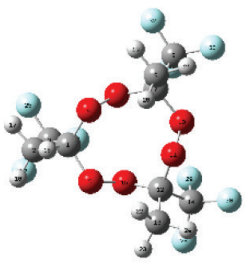

TATP3F

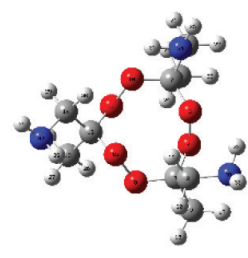

$\mathrm{TATPNH}_{2}$
TATPNO ${ }_{2}$ are shorter while the one of $\mathrm{TATPNH}_{2}$ is longer, since nitro and trifluoromethyl are electron-withdrawing groups which can decrease electron cloud densities of $\mathrm{O}-\mathrm{O}$ bonds. Considering structure, TATP3F and TATPNO ${ }_{2}$ have an excellent $\mathrm{O}-\mathrm{O}$ bond length and a stable structure. More information on standard orientation of every atom is presented in Supplementary Material in detail.

\section{Detonation performance}

In general, a high density causes better performance. For example, the detonation velocity of an explosive is proportional to its density, and the detonation pressure is proportional to its square..$^{1,11}$ The crystal densities of title compounds were presented in Table 2. It is reported ${ }^{31}$ that experimental density of TATP is $1.22 \mathrm{~g} \mathrm{~cm}^{-3}$, consistent with calculated value $1.28 \mathrm{~g} \mathrm{~cm}^{-3}$. This results suggested that computational methods are effective. In Table 2, their densities order is TATP3F > TATPNO $_{2}>$ TATPNH $_{2}>$ TATP. Due to N, O and $\mathrm{F}$ atoms, density of TATP derivatives are higher than TATP. Fluorine- and oxygen-rich groups have long been recognized as useful building blocks for the design and synthesis of superior energetic compounds and these building blocks provide energy density from molecules containing them. ${ }^{8,32}$ Calculation results showed that TATP3F's density is higher than HMX's $\left(1.90 \mathrm{~g} \mathrm{~cm}^{-3}\right){ }^{33}$

The value of the heat of formation must be obtained to estimate the performances of an explosive molecule through theoretical calculations. Their condensed phase heats of formation were shown in Table 3. It is reported ${ }^{34}$ that heat of formation of TATP is $-664.5 \mathrm{~kJ} \mathrm{~mol}^{-1}$, lower than the one of TATPNH ${ }_{2}$ and TATPNO with substituted energetic groups $-\mathrm{NH}_{2}$ and $-\mathrm{NO}_{2}$, respectively. The incorporation of three $-\mathrm{NO}_{2}$ groups into a molecule improves the heat of formation, which is consistent with a paper reported by Fei. ${ }^{35}$ It has also been found that compounds containing the halogen fluorine lower heats of formation. ${ }^{35,36}$ Calculation show that the value of TATP3F is least among them because of $\mathrm{F}$ atom replacing of $\mathrm{H}$ atom.

The detonation performances, such as detonation heat $(\mathrm{Q})$, detonation velocity (D) and detonation pressure (P), of title compounds were summarized in Table 4. Detonation performance of TATP is also obtained by the same method to compare. It reveals that detonation pressure and detonation velocity of title compounds with substituent groups range from 14.0 to $18.1 \mathrm{Gpa}$ and 6458 to $7699 \mathrm{~m} \mathrm{~s}^{-1}$ respectively, higher than that of TATP. Among the four compounds, $\mathrm{TATPNO}_{2}$ has relatively high values in both density and heat of formation, which contributes to its best performance. Detonation performance of TATPNO $\left(\mathrm{Q}=5424 \mathrm{~kJ} \mathrm{~kg}^{-1}, \mathrm{P}=23.7 \mathrm{Gpa}\right.$, $\left.\mathrm{D}=7699 \mathrm{~m} \mathrm{~s}^{-1}\right)$ is higher than that of TNT $\left(\mathrm{Q}=5418 \mathrm{~kJ} \mathrm{~kg}^{-1}\right.$, $\left.\mathrm{P}=19.0 \mathrm{Gpa}, \mathrm{D}=6950 \mathrm{~m} \mathrm{~s}^{-1}\right)$. ${ }^{38}$

\section{Electronic structure}

Electronic structure of title compounds can reflect photochemistry stability. In this paper, electronic structure includes electrostatic potential and energy gap $\triangle \mathrm{E}$ between HOMO and LUMO.

Figure 3. The optimized structure of TATP and its derivatives 
Table 2. The crystal densities of TATP and its derivatives compounds

\begin{tabular}{lcccccc}
\hline Compounds & $\begin{array}{c}\mathrm{M} \\
(\mathrm{g} \mathrm{mol})\end{array}$ & $\begin{array}{c}\mathrm{V}_{\mathrm{m}} \\
\left(\mathrm{cm}^{3} \mathrm{~mol}^{-1}\right)\end{array}$ & $\begin{array}{c}\text { As } \\
\left(\AA^{2}\right)\end{array}$ & $\mathrm{V}$ & $\begin{array}{c}\sigma_{\text {tot }}^{2} \\
\left(\left[\mathrm{kcal}_{\mathrm{mol}}^{-1}\right]^{2}\right)\end{array}$ \\
\hline TATP & 222 & 168.191300 & 254.10635 & 0.11708795 & 71.79535 & $\begin{array}{c}\rho_{\text {cry }} \\
\left(\mathrm{g} \mathrm{cm}^{-3}\right)\end{array}$ \\
TATPNH $_{2}$ & 267 & 199.000689 & 290.94175 & 0.22126548 & 122.5145772 & $1.28\left(1.22^{\mathrm{a}}\right)$ \\
TATPNO $_{2}$ & 357 & 223.557730 & 325.31637 & 0.24991823 & 151.2920261 & 1.35 \\
TATP3F & 384 & 191.360410 & 289.50833 & 0.23082580 & 64.87617670 & 1.62 \\
\hline
\end{tabular}

${ }^{a}$ The experimental values are taken from reference. ${ }^{31}$

Table 3. Condensed phase heat of formation of title compounds

\begin{tabular}{lcccccc}
\hline Compounds & $\mathrm{E}_{\text {zpe }}(\mathrm{au})$ & $\mathrm{H}_{\mathrm{T}}(\mathrm{au})$ & $\mathrm{E}_{0}(\mathrm{au})$ & $\Delta \mathrm{H}_{\mathrm{f}}(\mathrm{g})\left(\mathrm{kJ} \mathrm{mol}^{-1}\right)$ & $\mathrm{H}_{\text {sub }}\left(\mathrm{kJ} \mathrm{mol}^{-1}\right)$ & $\Delta \mathrm{H}_{\mathrm{f}}(\mathrm{c})\left(\mathrm{kJ} \mathrm{mol}^{-1}\right)$ \\
\hline TATP & 0.272287 & 0.017726 & -805.1280233 & $-561.8^{\mathrm{a}}$ & - & - \\
$\mathrm{CH}_{4}$ & 0.044539 & 0.003813 & -40.53396275 & $-74.6^{\mathrm{b}}$ & - & - \\
$\mathrm{CH}_{3} \mathrm{NO}_{2}$ & 0.049653 & 0.005281 & -245.0916544 & $-81.0^{\mathrm{b}}$ & - \\
$\mathrm{CH}_{3} \mathrm{NH}_{2}$ & 0.063782 & 0.004380 & -95.89388879 & $-23.5^{\mathrm{b}}$ & - & - \\
$\mathrm{CHF}_{3}$ & 0.024939 & 0.004429 & -338.3492076 & $-697.1^{\mathrm{b}}$ & - & - \\
TATPNO $_{2}$ & 0.281853 & 0.025110 & -1418.784392 & -544.5 & -4.4 & -585.9 \\
TATPNH & 0.325460 & 0.021707 & -971.2158113 & -435.5 & -4.2 & -464.7 \\
TATP3F & 0.201883 & 0.024032 & -1698.547977 & -2380.4 & 31.7 & -2412.1 \\
\hline
\end{tabular}

${ }^{a}$ The values are taken from reference. ${ }^{34}$ the values are taken from reference. ${ }^{37}$

Table 4. The calculated detonation performance of TATP and title compounds

\begin{tabular}{lccc}
\hline Compounds & $\mathrm{Q}\left(\mathrm{kJ} \mathrm{kg}^{-1}\right)$ & $\mathrm{D}\left(\mathrm{m} \mathrm{s}^{-1}\right)$ & $\mathrm{P}(\mathrm{Gpa})$ \\
\hline TATP & 3843 & 6107 & 10.0 \\
TATPNH $_{2}$ & 4179 & 6725 & 14.0 \\
TATPNO $_{2}$ & 5424 & 7699 & 23.7 \\
TATP3F $^{2}$ & 2123 & 6458 & 18.1 \\
TNT $^{\mathrm{a}}$ & 5418 & 6950 & 19.0 \\
\hline
\end{tabular}

${ }^{a}$ The values are taken from reference. ${ }^{38}$

Electrostatic potential of TATP and title compounds are shown in Figure 4, in which the legend for the range of the ESPs is -0.03 (left) to +0.03 (right). While the HOMO and LUMO orbitals were depicted in Figure 5, in which red color represents positive phase and the blue color represents negative phase. As can be seen from the figure, the LUMO orbitals mainly locate on substituted groups but the HOMO orbitals distribute approximately on the rings. The intramolecular charges transfer from the electron donor to the electron acceptor through the rings and substituted groups.

The values of energy gap $\Delta \mathrm{E}$ of TATP and its derivatives were shown in Table 5. The electron density of TATPNH ${ }_{2}$ seems to be distributed more evenly over the surface of the molecule and that would account for a lower impact sensitivity. ${ }^{29}$ However, the sequence of energy gap is TATP3F $>$ TATP $>$ TATPNH $_{2}>$ TATPNO $_{2}$, which is the reverse of chemical activity in order. In conclusion, TATPNO $_{2}$ has a good photochemistry stability according to electronic structure, and this result is consistent with geometrical structures in which $\mathrm{O}-\mathrm{O}$ bond length is shorter.

\section{CONCLUSION}

In recent years TATP has been used as an improvised explosive because its precursor chemicals are readily obtained and its synthesis is straightforward. However, it is not the high energy density material because of its lower detonation performance and higher sensitivity. This paper is expected to find some alternative materials and TATP derivatives were studied for this reason. They are TATP3F, TATPNH and TATPNO ${ }_{2}$, which were introduced with trifluoromethyl, amino and nitro groups to the TATP backbone, respectively.

The TATP derivatives were studied to improve TATP's performance on detonation performance or stability. TATP3F, TATPNH ${ }_{2}$ and TATPNO$_{2}$ were calculated by DFT methods based on 6-311G++ $(\mathrm{d}, \mathrm{p})$. Their geometrical structures, detonation performance and stability were investigated in detail.

Calculation suggests that in terms of both the detonation performance and stability, TATPNO${ }_{2}$ is better than others, especially

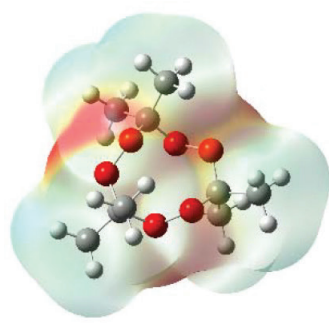

TATP

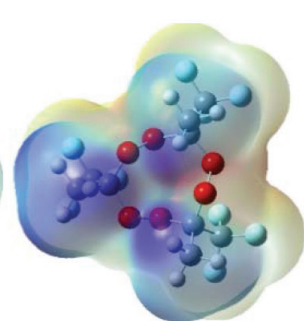

TATP3F

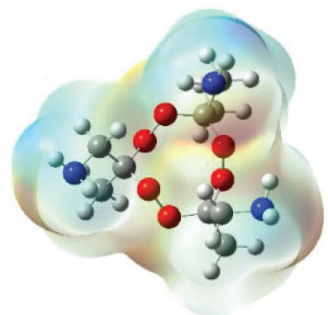

$\mathrm{TATPNH}_{2}$

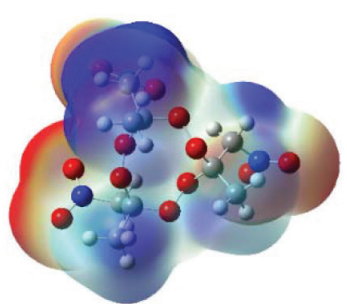

$\mathrm{TATPNO}_{2}$ 

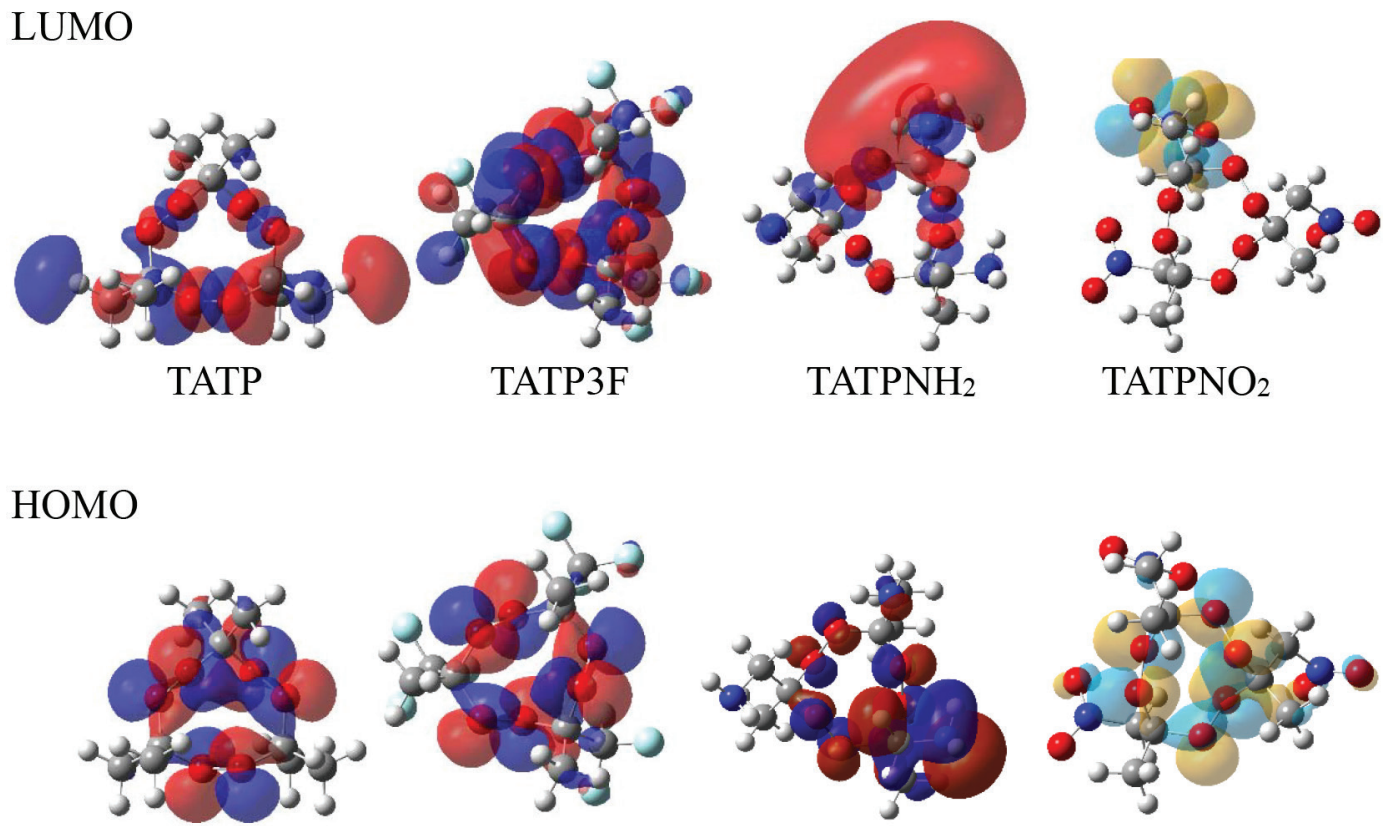

Figure 5. Highest occupied molecular orbital (HOMO) and lowest unoccupied molecular orbital (LUMO) of the four compounds

Table 5. Energy gap $\Delta \mathrm{E}$ of TATP and its derivatives

\begin{tabular}{lccc}
\hline Compounds & LUMO $(\mathrm{au})$ & HOMO $(\mathrm{au})$ & $\Delta \mathrm{E}(\mathrm{au})$ \\
\hline TATP & -0.00798 & -0.24687 & 0.23889 \\
TATP3F & -0.05756 & -0.29778 & 0.24022 \\
TATPNH $_{2}$ & -0.02056 & -0.23978 & 0.21922 \\
TATPNO $_{2}$ & -0.09867 & -0.29314 & 0.19447 \\
\hline
\end{tabular}

TATP. As far as stability is concerned, three nitros shorten O-O bond length and decrease energy gap $\triangle \mathrm{E}$ between HOMO and LUMO. At the same time, TATPNO ${ }_{2}$ has a relatively high density and heat of formation which are a contribution to power. Three nitros enclosing to rich-oxygen skeleton enhance oxygen content which helps to burn. Besides, detonation heat, detonation velocity and detonation pressure of TATPNO $2\left(\mathrm{Q}=5424 \mathrm{~kJ} \mathrm{~kg}^{-1}, \mathrm{P}=23.7 \mathrm{Gpa}, \mathrm{D}=7699 \mathrm{~m} \mathrm{~s}^{-1}\right)$ is higher than that of traditional explosive TNT $\left(\mathrm{Q}=5418 \mathrm{~kJ} \mathrm{~kg}^{-1}, \mathrm{P}=19.0 \mathrm{Gpa}\right.$, $\mathrm{D}=6950 \mathrm{~m} \mathrm{~s}^{-1}$ ). Therefore, $\mathrm{TATPNO}_{2}$ has a potential application as high energy density material because of its power, good stability, availability and rich-oxygen.

\section{SUPPLEMENTARY MATERIAL}

Standard orientations for atoms, harmonic frequencies of TATP and derivatives and calculation summaries of the Gaussian output parameters can be freely accessed at http://quimicanova.sbq.org.br, in pdf format.

\section{ACKNOWLEDGEMENTS}

This work is supported by Beijing Natural Science Foundation (2172037) and National Natural Science Foundation of China (No. 51673157 and 51503016). Z. C. M. also thanks the Science Research Foundation of Xijing University (Grant No. XJ16T02).

\section{REFERENCES}

1. He, P.; Zhang, J. G.; Wu, L.; Wu, J. T.; Zhang, T. L.; J. Phys. Org. Chem. 2017, 30, 1 .
2. Zhang, W.; Wang, K.; Li, J.; Lin, Z.; Song, S.; Huang, S.; Liu, Y.; Nie, F. ; Zhang, Q.; Angew. Chem. 2018, 57, 1.

3. Chen, J.; Yu, Y.; Li, Y. ; Pang, S.; J. Fluorine Chem. 2018, 205, 35.

4. Zhao, G.; Lu, M.; Quim. Nova 2013, 36, 513.

5. Oxley, J. C.; Smith, J. L.; Bowden, P. R.; Rettinger, R. C.; Propellants, Explos., Pyrotech. 2013, 38, 244.

6. Oxley, J. C.; Smith, J. L.; Chen, H.; Propellants, Explos., Pyrotech. 2002, 27, 209.

7. Dalinger, I. L.; Kormanov, A. V.; Suponitsky, K. Y.; Muravyev, N. V.; Sheremetev, A. B.; Chem. - Asian J. 2018, 13, 1165.

8. Semenov, V. V.; Shevelev, S. A.; Bruskin, A. B.; Shakhnes, A. K.; Kuz'min, V. S.; Chem. Heterocycl. Compd. 2017, 53, 728.

9. Tsyshevsky, R.; Pagoria, P.; Zhang, M.; Racoveanu, A.; Parrish, D. A.; Smirnov, A. S.; Kuklja, M. M.; J. Phys. Chem. C 2017, 121, 23853.

10. Contini, A. E.; Bellamy, A. J.; Ahad, L. N.; Propellants, Explos., Pyrotech. 2012, 37, 320.

11. Zhao, G. Z.; Lu, M.; Bull. Korean Chem. Soc. 2012, 33, 1913.

12. He, P.; Zhang, J. G.;Wang, K.; Yin, X.; Zhang, T. L.; J. Org. Chem. 2015, 80, 5643.

13. Frisch, M. J.; Trucks, G. W.; Schlegel, H. B.; Scuseria, G. E.; Robb, M. A.; Cheeseman, J. R.; Montgomery Jr., J. A.; Vreven, T.; Kudin, K. N.; Burant, J. C.; Millam, J. M.; Iyengar, S. S.; Tomasi, J.; Barone, V.; Mennucci, B.; Cossi, M.; Scalmani, G.; Rega, N.; Petersson, G. A.; Nakatsuji, H.; Hada, M.; Ehara, M.; Toyota, K.; Fukuda, R.; Hasegawa, J.; Ishida, M.; Nakajima, T.; Honda, Y.; Kitao, O.; Nakai, H.; Klene, M.; Li, X.; Knox, J. E.; Hratchian, H. P.; Cross, J. B.; Bakken, V.; Adamo, C.; Jaramillo, J.; Gomperts, R.; Stratmann, R. E.; Yazyev, O.; Austin, A. J.; Cammi, R.; Pomelli, C.; Ochterski, J. W.; Ayala, P. Y.; Morokuma, K.; Voth, G. A.; Salvador, P.; Dannenberg, J. J.; Zakrzewski, V. G.; Dapprich, S.; Daniels, A. D.; Strain, M. C.; Farkas, O.; Malick, D. K.; Rabuck, A. D.; Raghavachari, K.; Foresman, J. B.; Ortiz, J. V.; Cui, Q.; Baboul, A. G.; Clifford, S.; Cioslowski, J.; Stefanov, B. B.; Liu, G.; Iiskorz, P.; Komaromi, I.; Martin, R. L.; Fox, D. J.; Keith, T.; AlLaham, M. A.; Peng, C. Y.; Nanayakkara, A.; Challacombe, M.; Gill, P. M. W.; Johnson, B.; Chen, W.; Wong, M. W.; Gonzalez, C.; Pople, J. A.; Gaussian 09 (Rev. A.01), Gaussian Inc., Wallingford CT., 2009.

14. Calais, J.-L.; Int. J. Quantum Chem. 1993, 47, 101.

15. Abashkin, Y.; Russo, N.; Sicilia, E.; Toscano, M.; Theor. Comput. Chem. $\mathbf{1 9 9 5}, 2,255$. 
16. Krishnan, R.; Binkley, J. S.; Seeger, R.; Pople, J. A.; J. Chem. Phys. 1980, 72,650

17. Gao, H. X.; Ye, C. F.; Piekarski, C. M.; Shreeve, J. M.; J. Phys. Chem. C 2007, 111, 10718.

18. Fan, X. W.; Ju, X. H.; J. Comput. Chem. 2008, 29, 505.

19. Jin, X. H.; Zhou, J. H.; Wang, S. J.; Hu, B. C.; Quim. Nova 2016, 4, 467.

20. Lu, T.; Chen, F.; J. Comput. Chem. 2012, 33, 580.

21. Politzer, P.; Martinez, J.; Murray, J. S.; Concha, M. C.; Toro-Labbe, A.; Mol. Phys. 2009, 107, 2095.

22. Zhang, X.; Gong, X.; J. Chem. Eng. Data 2015, 60, 2869.

23. Byrd, E. F.; Rice, B. M.; J. Phys. Chem. A 2006, 110, 1005.

24. Suceska, M.; EXPLO5, version 6.01; Brodarski Institute, Zagreb, Croatia, 2013.

25. Suceska, M.; Propellants, Explos., Pyrotech. 1999, 24, 280.

26. Yu, Y.; Chen, J.; Zhang, R.; Li, Y.; Pang, S.; RSC Adv. 2017, 7, 23709.

27. Chi, W. J.; Li, L. L.; Li, B. T.; Wu, H. S.; J. Mol. Model. 2012, 18, 3695.

28. Murray, J. S.; Politzer, P.; Wiley Interdiscip. Rev.: Comput. Mol. Sci. 2011, $1,153$.
29. Hammerl, A.; Klapotke, T. M.; Noth, H.; Warchhold, M.; Holl, G.; Propellants, Explos., Pyrotech. 2003, 28, 165.

30. Oxley, J. C.; Smith, J. L.; Chen, H.; Propellants, Explos., Pyrotech. 2002, 27, 209.

31. Williams, M.; Drug Dev. Res. 2013, 74, 339.

32. Lempert, D. B.; Nechiporenko, G. N.; Soglasnova, S. I.; Dorofeenko, E. M.; J. Phys. Chem. B 2017, 11, 443.

33. Talawar, M. B.; Sivabalan, R.; Mukundan, T.; Muthurajan, H.; Sikder, A. K.; Gandhe, B. R.; Rao, A. S.; J. Hazard. Mater. 2009, 161, 589.

34. Sinditskii, V. P.; Kolesov, V. I.; Egorshev, V. Y.; Patrikeev, D. I.; Dorofeeva, O. V.; Thermochim. Acta 2014, 585, 10.

35. Fei, T.; Du, Y.; Pang, S.; RSC Adv. 2018, 8, 10215.

36. Kettner, M. A.; Karaghiosoff, K.; Klapotke, T. M.; Suceska, M.; Wunder, S.; Chem. - Eur. J. 2014, 20, 7622.

37. https://webbook.nist.gov/chemistry/, accessed in September 2018.

38. Politzer, P.; Murray, J. S.; Cent. Eur. J. Energ. Mater. 2011, 8, 209. 